\title{
Organization of higher education in context of digitalization: online learning experience at pandemic, development trends
}

\author{
Larisa Kobysheva ${ }^{1}$, Anna Luginina ${ }^{2}$, Nataliya Gafiatulina $^{3}$ and Yana Artamonova ${ }^{3 *}$ \\ ${ }^{1}$ Rostov State University of Economics, 347936, Taganrog, Russia \\ ${ }^{2}$ Kuban State Agrarian University named after I. T. Trubilin, 350044, Krasnodar, Russia \\ ${ }^{3}$ Southern Federal University, 344006, Rostov-on-Don, Russia
}

\begin{abstract}
It is highlighted in the study that digital transformations of the fourth industrial revolution are changing the modern human world, encouraging a person to acquire new competencies and become a qualified specialist in the digital economy. In connection with the progressive scientific and technical development, the institute of higher education is being transformed; new previously unknown approaches to the organization of higher education appear. One of such approaches is the introduction of online learning in higher education. The authors refer to the experience of 2020, when, during the pandemic of the new coronavirus infection, the whole world began to actively transfer work processes to a remote format, which also affected the institute of education. Universities around the world introduced distance learning using information technology, which helped students and faculty communicate at a distance. Based on the analysis, the following conclusions were drawn: digitalization of higher education in Russian universities is currently associated with the use of information and communication technologies in the educational environment and to a lesser extent with the use of electronic educational environment in the indirect interaction of students and teaching staff. In our opinion, it is necessary for the digitalization process to be consistent and not to be reduced to full distance learning, but to competently integrate information technology into the traditional learning process.
\end{abstract}

\section{Introduction}

Currently, we are witnessing a revolution that radically changes the usual way of life of a person - the way he lives, works and communicates with other people [1].

The fourth industrial revolution is associated with the active, high-speed, introduction of new innovative technologies that make changes in all spheres of human life. New technologies give rise to others, introducing them into the economy, culture, politics, public sector, education. The innovations brought by the fourth industrial revolution are primarily associated with digital transformations - autonomous vehicles, blockchain technologies, artificial intelligence, 3-D printing, virtual reality and much more.

\footnotetext{
* Corresponding author: janaserduchenko@mail.ru
} 
The new world with advanced digital technologies requires qualified, competitive personnel, which is the area of responsibility of the institution of education. In turn, general digitalization dictates the need to search for new approaches to the organization of higher education within the framework of progressive scientific and technological development: restructuring the educational process, redefining the role of the teacher, changing approaches to the management of the educational organization. In this regard, the interest of many scientists is attracted to the topic of changes in the educational system that occur under the influence of digitalization [2-4].

Existing publications show the benefits of using digital technologies in the educational environment, which make education open, mobile, accessible to a wide audience of students $[5,6]$. Some researchers are skeptical about the digitalization of education, expressed in a radical change in the content of educational programs for teaching students, which may lead to the formalization of professional training and a decrease in students' knowledge, especially when teaching in a distance form due to the lack of direct teacher-student contact [7].

Each work on this issue considers some specific aspect of digitalization of higher education and, in our opinion, there is currently a lack of research that would conduct a comprehensive analysis of this phenomenon in terms of its impact on higher education as a whole. The experience gained by higher education in 2020 in connection with the introduction of restrictions due to the pandemic of the new coronavirus infection and the transition of many universities to distance learning allows for a deep reflection of the organization of higher education in the context of digitalization. As part of this work, we will turn to the element of online learning in the context of a pandemic and the trends in the use of distance learning in universities in the future.

\section{Materials and Methods}

The institute of education has always attracted the attention of researchers. Modern scholars in their research are actively addressing the problems of reforming higher education, pointing out the ambiguity and inconsistency of modernization [8; 9]. They discuss the functions of higher education in reforming the education system, developing qualified personnel for the effective functioning of higher education, continuing education, and the formation of a market for educational services and products.

Among the issues of interest to researchers, there is also the issue of training digital personnel, in modern conditions [10]. An important place in research related to education issues is occupied by questions about the advantages and problems of digitalization of higher education: blended learning models, the creation of a digital educational environment, and the transition to online learning [11].

The term "digitalization" itself is being transformed and acquires new definitions. If earlier the process of digitalization was understood as the transition from paper to electronic media, now this concept is changing and acquiring a slightly different semantic contour, where social relations based on the use of digital communication and digital media are being transformed. Thus, digitalization of education today is not just the use of information technologies in the educational process; it is something more - a change in the educational paradigm, educational technologies, and a change in the content, forms and methods of the learning process in the context of digital reality.

In order to understand how the organization of higher education takes place in the context of digitalization, it is necessary to understand what higher education is as a social institution, what digitalization trends in education can be traced, and what impact they have on higher education, how the management of an educational organization is changing in the context of digitalization. 
Considering higher education as one of the main social institutions, we rely on the theory of institutionalization by P. Berger and T. Luckmann. This theory makes it possible to evaluate higher education from the point of view of the regulatory process of the socialization of individuals based on existing formal and informal norms and rules. This approach also allows us to analyze pedagogical and managerial decisions at all levels of educational structures.

Speaking about the digitalization of higher education, we cannot ignore changes in the structure of the educational process and functions of education due to the active introduction of innovative technologies into the educational process. In this regard, we consider higher education using the structural-functional approach developed by E. Durkheim and $\mathrm{T}$. Parsons.

The problem of digitalization of society and education acquired particular importance in 2020, when, during the pandemic of the new coronavirus infection, the whole world began to actively transfer work processes to the remote "home office" mode. Educational organizations were no exception, since the educational process could not be paused for a long time, distance learning was conducted with the use of various educational technologies that allowed the interaction of students and teaching staff indirectly (at a distance).

Thus, the analysis of the sources on the problem field of research and the experience of 2020 indicate that there is a transformation of the institute of higher education associated with the growing demand for online education. In this regard, we believe that it is important to refer to the experience gained in distance learning during pandemic, which will help us assess the digitalization of higher education and determine further trends in the development of this process.

\section{Results}

Before assessing the digitalization of higher education, it is necessary to define what we mean by higher education. In our opinion, education is one of the main social institutions that is responsible for the socialization of the individual. P. Berger and T. Luckmann noted that it is a social institution that has the role of immersing an individual in the world of rules and norms, the role of regulating his behavior. Within the framework of any social institution, the subjects are given social roles - behavioral models that dictate to the subjects a certain order of actions in a particular situation. If we turn to the institution of education, we will see that the subjects of the educational process perform one or another role: the role of a student, the role of a teacher, the role of an administrative employee. In accordance with the prescribed roles, the subjects of the educational process perform a prescribed set of actions. As a social institution, education has the function of social control. As for higher education, here we also note that the main function of higher education is the qualified preparation of students for employment. That is, the institution of higher education provides the country's economy with human resources. However, since roles and rules correspond to certain situations, then if the situation changes, the rules change and the institution is transformed.

Thus, considering higher education from the point of view of the institutional approach allows us to investigate what norms and rules have developed within the framework of this institution, and how, on the basis of these norms, the interaction of the subjects of the institution of higher education occurs.

The digitalization process introduces changes in social reality, which means that it entails the transformation of rules and norms, in our case, rules and norms in the social institution of higher education. Digitalization of higher education is the transformation of the educational process by integrating information resources into the educational process. This 
process includes the digital infrastructure of education, the development of digital teaching materials, the creation of digital services including digital assessment, the creation and dissemination of new models for organizing educational work (see Fig. 1).

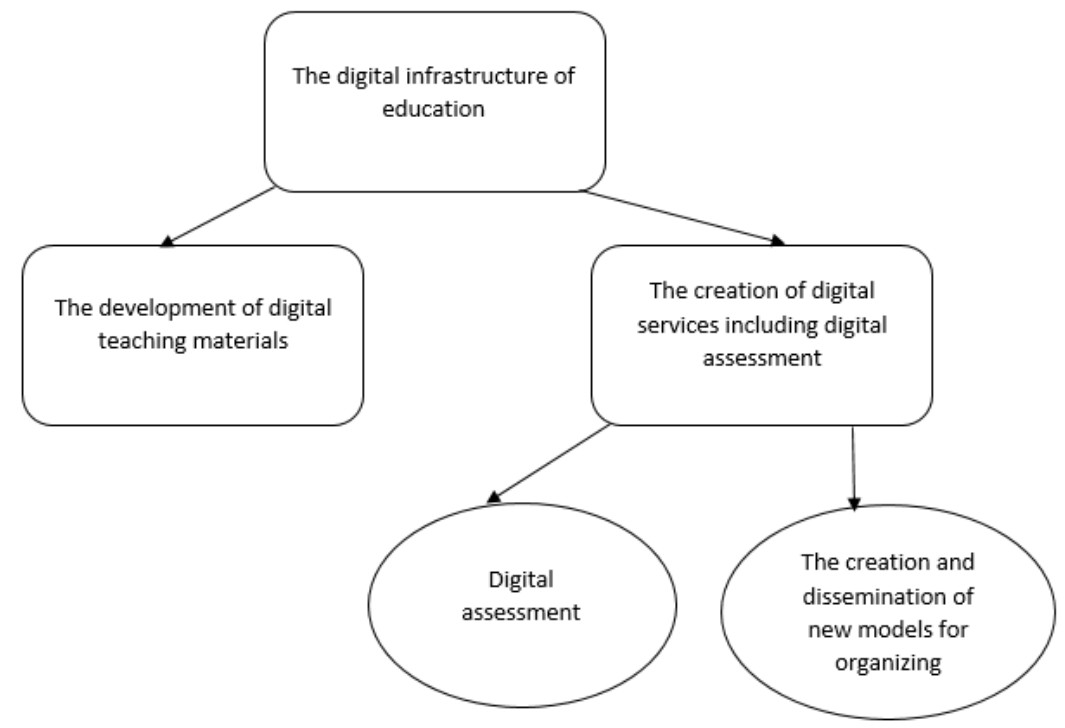

Fig. 1. The transformation of the educational process by integrating information resources into the educational process.

The organization of higher education in the context of digitalization is changing dramatically: the educational process and the process of managing an educational organization are being transformed; student social practices are also undergoing changes (see Fig. 2) [11].

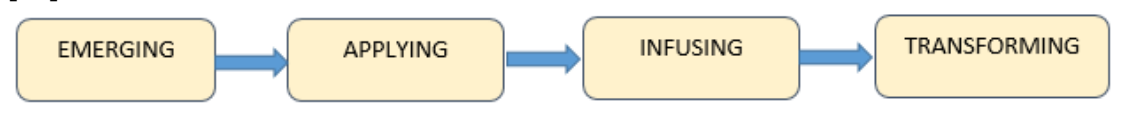

Fig. 2. Stages of ICT development that educational systems through use and adoption of ICT.

Despite the fact that many universities do not strive to support the digitalization of higher education, technological progress affects the use of technical means and information technologies in higher education. At present, for a visual demonstration of the material being studied teachers use such information tools as an electronic projector and an interactive board. Lectures and practical lessons accompanied by presentation materials, and videos make the educational process visual.

Various Internet services allow students and teachers to interact at a distance: performance of independent work by students and verification of students' work by posting material in personal cabinets with the ability to access for evaluation of work by the teaching staff. Universities have digital repositories where employees of the organization can post their publications, as well as students' term papers and graduate qualification works, which makes it possible for everyone who has access to the repository to view the materials. For employees and students of universities access to a number of scientometric databases is provided: the Russian Science Citation Index (RSCI), Scopus, and Web of Science. In the educational process, electronic journals of attendance at classes and an electronic system of point-rating assessment of students are also used. Some educational institutions are actively using digital technologies based on artificial intelligence: here, of course, foreign universities 
are more successful, foreign universities, where chat bots programmed to answer standard questions and provide technical information are used for tutor support of students [12-14]. Some Russian universities also use this practice: for example, the work of a chat bot for applicants when entering a university. Communicating with applicants, the virtual assistant quickly finds answers to questions of interest to young people.

As we can see, these technologies are integrated into the traditional learning process at the university and do not cancel the traditional form of education, where students and teachers meet offline. In addition to this blended learning format, there are fully distance learning forms (online education), where the transition of the educational process to the online mode is expected. As part of online learning, teachers develop and implement online courses using special Internet services (platforms: Coursera, Open Education). Within the framework of such training, communication of all subjects of the educational process is carried out only in electronic mode: electronic timetable, electronic assessment, educational records, and electronic grade books. On the one hand, this form of education makes education open, mobile and individualized for various categories of citizens due to the fact that the educational process takes place in a virtual environment through information and communication technologies. It is also worth emphasizing the dynamism and interactivity of this form of work, which allows students to be actively involved in educational activities. The positive aspects should include the fact that e-learning materials can be reused, saving teachers' time to prepare for classes. Despite the positive points, there are also controversial points. For example, online learning requires special competencies from teachers and students; for the effective operation of electronic portals, constant technical support is required, which entails the creation of structural units at the university that can provide such support. Of course, this is reflected in the management processes of the educational organization.

It should be noted that the use of information and communication technologies in the traditional educational process, the introduction of online courses and the format of distance learning require the creation of a specialized digital educational environment. Such an environment should combine two aspects of the reproduction of knowledge: convenient creation and consumption. In addition, the virtual educational environment should provide quick access to information materials, allow participants in the educational process to build communication with the possibility of feedback. Russian universities use the Moodle platform as such an environment. On this platform, teachers can create materials for lectures and practical tasks, post photos, videos and audio content, conduct online lectures, seminars and online consultations, check test assignments, and grade students.

The aspects of digitalization of education that we have listed are changing the role models of teacher behavior: the teacher becomes a provider of content and resources in the digital educational environment. Many teachers are very worried about these transformations and experience discomfort in such working conditions [15]. Digitalization of higher education is also reflected in the management system of the university, introducing new structural units to serve the digital educational environment.

Despite the fact that modern students very quickly master the digital virtual space of the Internet as a whole, the question arises, what is the attitude of students to the educational digital environment?

In this work, we deal with the assessment of students in relation to the distance-learning format, which has become actively spread in the context of the pandemic. A secondary analysis of research data carried out by the All-Russian Center for Public Opinion (VTsIOM) and the All-Russian public organization "Russian Professors' Assembly" (RPS) allows us to give such an assessment. 
In unfavorable epidemiological conditions, universities were forced to move to distance learning, and therefore student educational practices began to transform: all classes began to be conducted through the monitor screen, mass student events, conferences, and round tables were transferred to the online format.

The results obtained in the course of the RPS study indicate that many Russian universities have their own distance learning system, which made it possible to quickly switch to a distance-learning format. Nevertheless, it should be noted, that until March 2020, distance-learning systems were used irregularly in the educational process: $1 / 4$ of the surveyed students noted that until March 2020 working on this resource was optional. Moreover, about $70 \%$ of the respondents indicated that before the introduction of the forced distance-learning program, they had no personal experience of receiving education in a distance format (67.6\%). The transition to distance learning caused mixed feelings among students: $23 \%$ of respondents experienced fear, $21 \%$ - confusion, but $1 / 3$ of respondents indicated that they were initially positive about the online form. To the positive aspects of distance learning, students attribute the saving of time spent on the road to the place of study; they also managed to improve their skills in working with various electronic resources.

According to VTsIOM, based on the experience of working in a distance format, more than $50 \%$ of students noted an increase in the workload on teachers in the distance-learning format, $1 / 4$ of the students felt that the workload had decreased. The level of teaching in the distance format itself was assessed by more than half of the students as high or rather high, $32 \%$ indicated that the distance format was at an intermediate level; only $12 \%$ of students gave low marks to the level of education in the coronavirus period. At the same time, the overwhelming majority of students $(72 \%)$ are satisfied with the way distance education is organized at their university in the context of the spread of COVID-19.

In general, the analyzed data concerning distance learning during the pandemic allowed us to draw the following conclusions: the speed of transfer of universities to distance learning ensured the continuity of the learning process in higher education and the possibility of applicants entering the university in the summer. Despite the fact, that many universities have their own distance learning system, it is not constantly used in the learning process. It is worth saying that the majority of students assess their distance learning experience satisfactorily, but note that now they are faced with technical problems, as well as motivation, selforganization and self-discipline.

\section{Conclusions}

Summing up the results of this study, we note that the digitalization of higher education in Russian universities is currently associated with the use of information and communication technologies in the educational environment and is less expressed in the use of an electronic educational environment in the indirect interaction of students and teaching staff.

The experience of distance learning during pandemic has shown that online learning transforms the educational process, changes the roles of participants in the educational process and the rules for their interaction. Despite their own distance learning system, universities do not completely switch to it, but prefer a blended learning format, including only individual courses or modules in the curricula of basic educational programs. Students are ready to work in the framework of distance learning, but nevertheless, when conducting certain types of classes: seminars, laboratories, exams, educational and industrial practices, they tend to the traditional form of education.

Thus, our analysis shows that digitalization of higher education is transforming the usual educational environment and changing everyday student practices. The lessons of the 
pandemic have shown that most higher education institutions can quickly mobilize themselves and use their existing resources in distance learning. However, it should be recognized that digital education with quality online courses and an associated digital learning environment is very costly and entails changes in the qualification requirements for faculty. In this regard, in our opinion, it is necessary for the digitalization process to be consistent, not to be reduced to full distance learning, but to competently integrate information technologies into the traditional learning process.

\section{References}

1. K. Schwab, The fourth industrial revolution (Eksmo, Moskow, 2016)

2. E.G. Echenique, L.M. Molías, M. Bullen, RUSC, Universities and Knowledge Society Journal 12(1), 1-11 (2015) doi: 10.7238/rusc.v12i1.2078.

3. A.V. Kuchumov, E.V. Pecheritsa, A.T. Kirillov, A.V. Chaikovskaya, Current problems of the higher education development in the Russian Federation considering the digitalization processes, Conference 2019, (SPBPU IDE '19), St. Petersburg, 3373-3410 (2019) doi: 10.1145/3372177.3373341.

4. Alexander J. Means, Learning to Save the Future: Rethinking Education and Work in an Era of Digital Capitalism (Routledge, New York, 2018) doi: 10.4324/9781315450209.

5. E.P. Fedorova, E.I. Skobleva, Application of Blockchain European Journal of Contemporary Education. 9(3), 552-571 (2020) doi: 10.13187/ejced.2020.3.552.

6. N. Dabbagh, A. Kitsantas, Internet and Higher Education 15, 3-8 (2012) doi: 10.1016/j.iheduc.2011.06.002.

7. A.I. Rakitov, Higher education in Russia 27(6), 41-48 (2018)

8. A.C. McCormick, International Journal of Chinese Education 8(1), 60-72 (2019) doi: 10.1163/22125868-12340105.

9. V.V. Bulgakov, Higher education in Russia 28(8-9), 100-109 (2018) doi:10.31992/08693617-2019-28-8-9-100-109.

10. E.B. Gerasimova, A.A. Kurashova, M.V. Tipalina, M.V. Bulatenko, N.V. Tarasova, On the Horizon ahead-of-print (ahead-of-print). (2019) doi: 10.1108/OTH-07-2019-0043

11. H.K. Dubey, A. Singh, S. Dubey, International Journal of Advance and Innovative Research 6(1(X)-1), 97-99 (2019)

12. Allison Dee Ann., Library Hi Tech 30(1), (2011) doi: 10.1108/07378831211213238.

13. O. Zabolotska, N. Zhyliak, N. Hevchuk, N. Petrenko, O. Alieko, Journal of Optimization in Industrial Engineering 14(1), 43-50 (2021)

14. Bicknell-Holmes Tr., Chat \& Instant Messaging for Reference Services: a Selected Bibliography (Faculty Publications, UNL Libraries. 2008).

15. J.Dr. Sappey, St. Relf, Journal of University Teaching \& Learning Practice 7(1), 1-17 (2010) 